\title{
ESTÁGIO DE PÓS-DOUTORADO EM TERRAS LUSITANAS: RELATO DE EXPERIÊNCIA
}

\section{POST DOCTORATE INTERNSHIP AT PORTUGUESE LAND: EXPERIENCE REPORT \\ PASANTÍA DE POSTDOCTORADO EN TIERRAS LUSITANAS, UN RELATO DE EXPERIENCIA}

\section{Claudia Machado*}

*Membro do Centro de Investigação em Didática e Tecnologia na Formação de Formadores da Universidade de Aveiro. Pós-doutora pelo Departamento de Educação e Psicologia da Universidade de Aveiro. PhD em Ciências da Educação, com Especialização em Tecnologias Educacionais, pela Universidade do Minho. Aveiro, Portugal.

E-mail: aclaudiamachado@ua.pt

Recebido para publicação em: 25.6.2019 Aprovado em: 10.7.2019

\section{Resumo}

Este artigo apresenta relato de experiência de estágio de pós-doutorado realizado em Portugal, na Universidade de Aveiro. Durante a realização do estágio, foram desenvolvidas várias atividades que fizeram desse momento um proveitoso caminho, que abriu os horizontes, aguçou a curiosidade científica e o compromisso com a pesquisa. O foco do trabalho de pesquisa desenvolvido durante o estágio foi o uso das redes sociais por estudantes de nível superior. Conclui-se pelo estímulo a mais pesquisadores desenvolverem estágios em instituições de ensino portuguesas.

Palavras-chave: Relato. Estágio. Pós-doutorado. Portugal.

\begin{abstract}
This article presents a report of postdoctoral internship experience held in Portugal at the University of Aveiro. During the internship, the development of several activities created a useful path which opened the horizons, sharpened scientific curiosity and committed to research. The focus of the research work developed during the internship was the use of social networks by higher education students. It concludes by encouraging more researchers to develop internships in Portuguese educational institutions.
\end{abstract}

Keywords: Report. Internship. Postdoctorate. Portugal. 


\section{Resumen}

Este artículo presenta un recuento de la experiencia de pasantía postdoctoral realizada en Portugal en la Universidad de Aveiro. Durante la pasantía, se desarrollaron varias actividades que hicieron que este momento fuera un provechoso camino, que abrió los horizontes, agudizó la curiosidad científica y el compromiso con la investigación. El enfoque del trabajo de investigación desarrollado durante la pasantía fue el uso de redes sociales por estudiantes de nivel superior. Se concluye por alentar a más investigadores a desarrollar pasantías en instituciones educativas portuguesas.

Palabras clave: Relato. Pasantía. Postdoctorado. Portugal.

\section{Introdução}

A oportunidade de dar prosseguimento ao desenvolvimento de um trabalho de pesquisa autônomo é uma responsabilidade e um desafio "que fundamenta-se na necessidade de nos mantermos atualizados e produzirmos conhecimento útil para a sociedade" (SILVA, 2012). Assim, após concluir o doutorado, em 2015, um tema que começou a chamar a atenção foi a utilização das redes sociais. A partir de então, constatou-se que havia estudos pontuais que tratavam da utilização das redes sociais pelos estudantes do ensino superior na perspectiva da privacidade e segurança. Nesse sentido, e procurando contribuir com a produção de conhecimento sobre o estado atual da utilização das redes sociais por parte dos estudantes, bem como o favorecimento de práticas de utilização das redes sociais com responsabilidade e segurança, começou-se a elaborar o plano de trabalhos com a finalidade de realizar um estágio de pós-doutorado na Universidade de Aveiro (UA).

A escolha pela UA se deu pelo reconhecimento da competência e qualidade dos docentes, pela excelência em pesquisa, pela ampla oferta formativa e pelo alto nível de interação com outras instituições. Assim, a UA assume-se como importante referência no panorama europeu e mundial. Os cursos e projetos de pesquisa possuem um grande reconhecimento internacional.

Nesse sentido e após elaborar o plano de trabalhos, buscou-se o contato por e-mail, em abril de 2016, com a professora Doutora TMBC, pelo qual além de apresentação e demostração do interesse em realizar o pós-doutorado na UA sob sua supervisão, constava em anexo o plano de trabalhos e o currículo da autora. No mesmo dia, por parte da mesma, enviou resposta ao e-mail disponibilizando-se para o que seria a primeira conversa, a qual aconteceu dois dias depois.

No primeiro encontro, foram discutidos alguns pontos a serem considerados no plano de trabalhos e ponderadas algumas alterações a serem realizadas, e após as alterações efetuadas e o preenchimento dos formulários necessários, realizou-se a candidatura ao estágio de pós-doutorado no dia 5 de maio. Tendo sido aceito pelo Conselho Científico da UA, o estágio teve início em 1 de junho, sendo desenvolvidas, desde então, diversas atividades no âmbito do mesmo. O período do estágio foi de junho de 2016 a maio de 2019. 
Encontram-se aqui descritas as atividades desenvolvidas e a produção intelectual produzidas no período do estágio, atendendo às metas expostas do plano de atividades. O objetivo é estimular outros pesquisadores a realizarem estágios em instituições de ensino, não só pela facilidade da língua, mas pela "abertura de espírito, curiosidade científica e postura inovadora", que "fazem desse 'mergulho' internacional um proveitoso caminho a percorrer" (SILVA; FERREIRA; APOSTOLIDIS, 2014, p. 786).

\section{0 estágio de pós-doutorado - o projeto BeSafe}

0 letramento digital engloba, além do acesso aos meios digitais e às tecnologias da informação e comunicação (TIC), a compreensão e avaliação crítica dos conteúdos
A popularidade das redes sociais é reconhecida e atravessa fronteiras de idade, gênero, cultura ou estatuto social. Sendo um espaço no qual as pessoas tendem a ser mais descontraídas, as redes sociais, como fenômeno, levantam, no entanto, questões que importa conhecer e refletir, principalmente, sobre gestão de segurança e da privacidade.

Tendo em conta a importância da temática, o projeto BeSafe esteve alinhado com duas iniciativas do governo Português, nomeadamente, a Agenda Portugal Digital (2012) e o Portugal INCoDe.2030 (PORTUGAL..., 2017), que têm como pano de fundo estimular o letramento digital dos portugueses. Nesse sentido, considera-se que o letramento digital engloba, além do acesso aos meios digitais e às tecnologias da informação e comunicação (TIC), a compreensão e avaliação crítica dos conteúdos, contribuindo, assim, para que os portugueses exerçam plenamente a sua cidadania ao utilizarem a internet de forma positiva, informada e segura.

O público-alvo do projeto foram os estudantes do ensino superior de Portugal. Assim, teve como objetivo geral contribuir para que os estudantes do ensino superior viessem a exercer plenamente a sua cidadania ao utilizarem as redes sociais de forma positiva e informada, sobretudo quanto à privacidade e à segurança. Assumiram-se como questões de pesquisa as seguintes:

- Quais são os conhecimentos, as práticas e as perspectivas dos estudantes do ensino superior em relação ao conhecimento dos perigos das redes sociais?

- Até que ponto os estudantes do ensino superior têm consciência dos riscos e perigos que correm ao disponibilizarem informações pessoais, publicarem fotos, comentários, vídeos e a partilharem publicações nas redes sociais?

- Como promover a divulgação da temática "Perigos das Redes Sociais" junto aos estudantes do ensino superior?

Subjacentes às questões de pesquisa, estão os seguintes objetivos:

- Identificar os conhecimentos, práticas e perspectivas dos estudantes do ensino superior relativamente ao conhecimento dos perigos das redes sociais; 
- Identificar até que ponto os estudantes do ensino superior têm consciência dos riscos e perigos que correm ao disponibilizarem informações pessoais, publicarem fotos, comentários, vídeos e a partilharem publicações nas redes sociais;

- Promover palestras sobre a temática "Perigos das Redes Sociais" junto aos estudantes.

E para que os objetivos fossem alcançados, foi elaborado um plano de trabalho (Figura 1), no qual constavam as ações a serem desenvolvidas, bem como o período.

Figura 1 - Resumo geral das atividades inicialmente planeadas no estágio

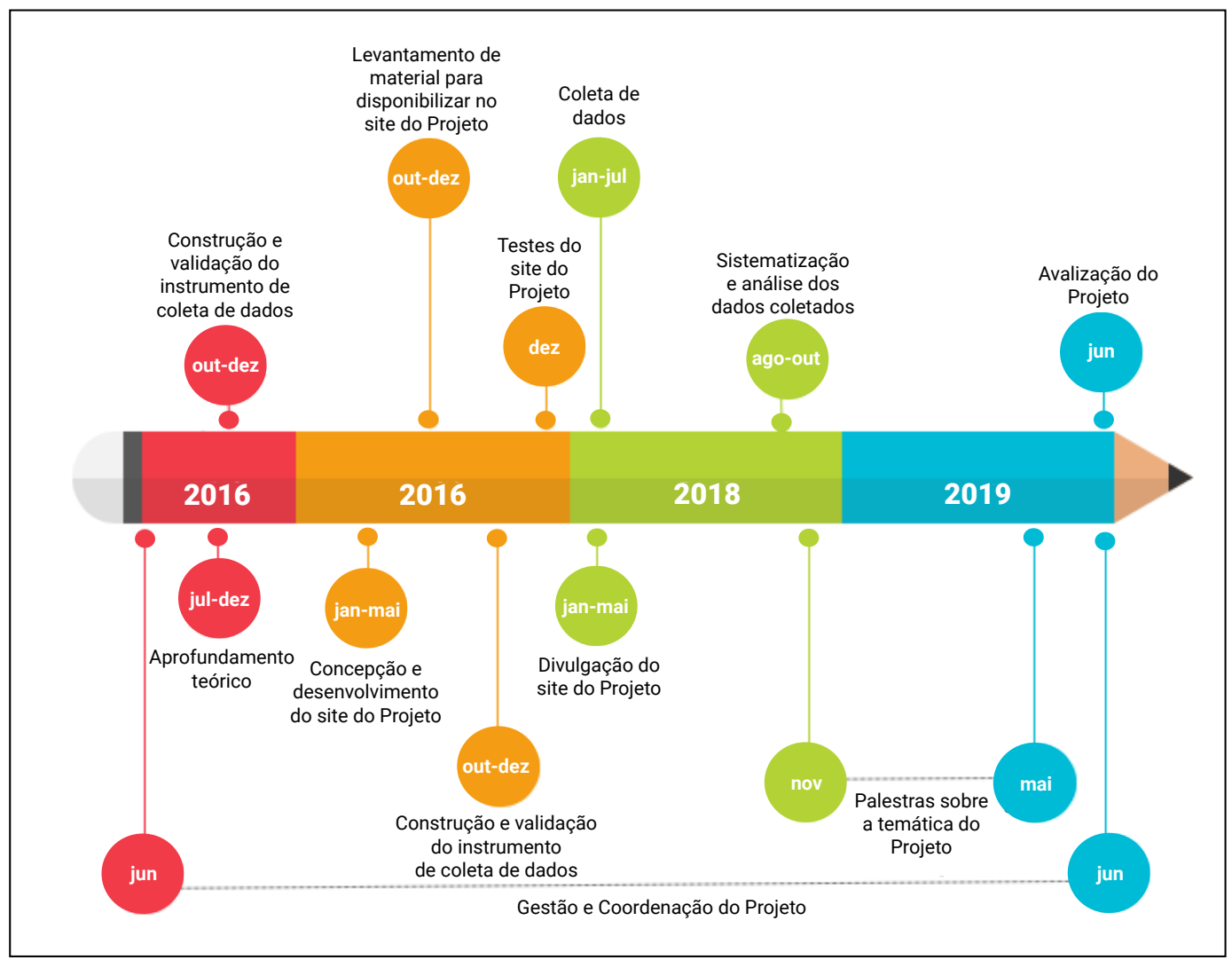

Fonte: Elaboração própria.

\section{Atividades desenvolvidas}

Para o desenvolvimento do estágio e de acordo com o plano de trabalhos, foram realizadas várias atividades, elencadas a seguir. Paralelamente, houve a participação em diversos eventos de formação e de interação com a comunidade científica, de modo a reforçar conhecimentos e competências no domínio da pesquisa científica e da sua disseminação. Importa referir que a primeira atividade realizada foi o estabelecimento de uma agenda de reuniões preliminares com a supervisora e definição do regime de trabalho e estudos. 
No âmbito das atividades de pesquisa, a revisão de literatura incidiu sobre trabalhos publicados (artigos, livros, teses e dissertações) que versam sobre a utilização das redes sociais no contexto mundial e em Portugal e sobre questões relativas a privacidade e segurança nas redes sociais, procurando obter um panorama geral do que vem acontecendo no contexto mundial e em Portugal. Contemplou também uma revisão de literatura alargada no que concerne à metodologia de pesquisa, permitindo apurar diversos procedimentos, em especial no que concerne à coleta e análise de dados.

Mais além, foram realizadas a construção, a validação e a implementação dos questionários dos estudantes com base em revisão de literatura, no âmbito da metodologia de pesquisa e dos processos de construção e validação de instrumentos de coleta de dados, nomeadamente, o questionário, e avançou-se para a construção e validação do mesmo. Elaborou-se o planejamento do questionário, levando-se em consideração os objetivos do estudo e da aplicação das perguntas, as dimensões de análise a considerar, bem como o tempo necessário para aplicação. Foram também definidas as perguntas e elaborado um texto introdutório com apresentação e objetivos do estudo, bem como a declaração de consentimento. Sendo, por último, realizada a formatação do questionário.

questionário

foi aplicado a

uma amostra

probabilística

representativa

do universo de

estudantes do

ensino superior

português
O questionário serviu para identificar conhecimentos, práticas e perspectivas dos estudantes do ensino superior em relação ao conhecimento dos perigos das redes sociais. Foram recolhidas informações tendo como base uma série de questões planificadas e ordenadas, que foram respondidas on-line pelos sujeitos (CARMO; FERREIRA, 2008; COHEN; MANION; MORRISON, 2007; HILL; HILL, 2000; MARCONI; LAKATOS, 2003). Nesse sentido, na elaboração dos questionários garantiu-se o seu rigor, procurando definir os tipos de perguntas e de respostas adequados, as escalas de medida a utilizar e os métodos para análise dos dados. Os questionários foram submetidos a um processo de validação de conteúdo e de forma por especialistas. Após a introdução dos acertos considerados necessários, procedeu-se à redação da versão final do questionário. Em seguida, realizou-se a implementação do questionário no sistema on-line de questionários da UA.

Na fase de aplicação, coleta e análise de dados do inquérito por questionário, o mesmo foi aplicado a uma amostra probabilística representativa do universo de estudantes do ensino superior português. Assim, a fim de fazer chegar o questionário aos estudantes, foram enviadas mensagens de correio eletrônico às Instituições de Ensino Superior Portuguesas e Associações Acadêmicas/Associações de Estudantes com a solicitação de colaboração na divulgação. Para além disso, realizou-se divulgação na página do Facebook do projeto BeSafe.

O processo de coleta de dados iniciou em janeiro e finalizou em julho de 2018 . 0 período alargado deu-se pela fraca participação dos estudantes na resposta ao ques- 
tionário. Nesse sentido, como forma de incentivar a participação dos estudantes, foram oferecidos três prêmios para serem sorteados no início de agosto, após finalizar o prazo para respostas, que foi em 30 de julho de 2018. Para a análise de dados foi utilizado o software Microsoft Excel, visto que o banco de dados transferido pelo sistema on-line de questionários da Universidade de Aveiro disponibiliza o arquivo no formato .xIsx. Além disso, a quase totalidade do questionário foi de questões fechadas e para as poucas questões abertas foram realizadas análises de conteúdo.

Para levantamento do material a disponibilizar no website do projeto, realizou-se um estudo minucioso dos materiais (textos, vídeos, imagens, etc.) sobre a temática Privacidade e Segurança nas Redes Sociais, envolvendo as etapas de seleção e classificação do material e análise, visando atender às características, necessidades e aos objetivos do projeto.

O website do projeto BeSafe foi fundamentado por uma proposta pedagógica e tecnológica. Nesse sentido, no planejamento do website, foram levados em consideração os objetivos do projeto e o público-alvo. Foram definidas as cores, a estrutura do menu e das páginas. Fez-se a escolha das informações e materiais (texto, vídeo, imagem) a serem disponibilizados. Foi desenvolvida a estrutura do website e foram inseridos os conteúdos. E para a implantação do website do projeto, procedeu-se à compra do domínio projetobesafe.pt, o qual foi hospedado na Hostgator ${ }^{1}$. Após as configurações, colocou-se o site on-line.

Para avaliar a usabilidade do website do projeto, adotou-se a grelha concebida por Bottentuit Junior (2010), a qual foi dividida em três grupos: (I) Interface e aspectos visuais/gráficos; (II) Navegação e arquitetura da informação; e (III) Conteúdos, interesse e potenciais a nível pedagógico. A grelha de avaliação foi concebida visando à facilidade de uso e por isso não foi extensa (RUBIN; CHISNELL, 2008). Após a concepção da grelha, procedeu-se o envio de um e-mail com a solicitação a 3 (três) especialistas na área da Tecnologia Educativa para a avaliação do website. No e-mail constava, para além da solicitação, o link que dava acesso ao site e a grelha de avaliação que foi disponibilizada on-line.

Diante das considerações dos avaliadores, procederam-se algumas alterações no site, principalmente no que se refere à quantidade de informação disponível. Foram inseridos alguns dados relativos aos resultados parciais do questionário aplicado aos estudantes do ensino superior e também inseridos mais links para além dos do menu de navegação. Outro aspecto que sofreu alteração está relacionado à inserção do e-mail de contato do projeto na página "Contactos". No que se refere aos itens do menu "Produtos", optou-se por retirar o submenu "Publicações", visto que ainda não existem informações para disponibilizar. Para melhorar a usabilidade do site nos dispositivos móveis, realizou-se uma revisão, visando melhorar a disposição dos links. Assim, os resultados da avaliação da usabilidade do site serviram para realizar alterações importantes visando deixar o website melhor para os utilizadores. Importa referir que, após a avaliação da usabilidade, foram inseridos, no 
decorrer do estágio, mais conteúdos, nomeadamente vídeo sobre as redes sociais, textos e informações. Após a avaliação da usabilidade, o website do projeto foi disponibilizado e divulgado quer pelas redes sociais, quer pelos eventos de caráter científico com a participação da autora.

Criou-se uma página no Facebook que serviu para divulgar o website do projeto, os eventos, bem como publicações, vídeos e notícias relacionados com o projeto. Em meados de setembro de 2018, foi criado um vídeo que tratava da temática "Privacidade e Segurança nas Redes Sociais", disponibilizado no website e na rede social Facebook do projeto.

Importa referir que os encontros presenciais de trabalho com a supervisora foram determinantes para que o estágio fosse desenvolvido com qualidade e rigor. Tendo sido uma média de seis encontros por ano, perfazendo um total de 18 encontros.

Foi elaborado um diapositivo utilizado em duas aulas e em uma palestra, no qual constavam, para além da temática "Privacidade e Segurança nas Redes Sociais", os resultados dos questionários aplicados aos estudantes.

Durante o estágio, foram realizadas atividades de divulgação científica, sendo 1 (um) texto publicado em periódico: (MACHADO; BETTENCOURT, 2018c); 4 comunicações em livros de atas: (MACHADO; BETTENCOURT, 2017c, 2018a, 2018b, 2018d); e 3 pôsteres apresentados sem publicação de texto: (MACHADO; BETTENCOURT, 2017a, 2017b, 2018e). Houve duas comunicações a convite dos organizadores de eventos científicos e não publicadas, sendo um dos eventos, o "Under Investigation: Psychology \& Education" 2018/19 ( $5^{\text {th }}$ ed.), que teve lugar na Universidade de Aveiro, no dia 28 de novembro de 2018, e o outro, o Congresso E-Tech Portugal, no painel "Cidadania e segurança digital - qual o papel da escola?", que teve lugar em Setúbal, no dia 12 de maio de 2018.

No que se refere às atividades de interação com a sociedade, realizaram-se colaborações com publicações periódicas de caráter científico por meio da emissão de quatro pareceres, a seguir:

- 2019 - Emissão de 1 parecer para a revista "Boletim Técnico do SENAC", editada pelo Serviço Nacional de Aprendizagem Comercial (SENAC) - ISSN 2448-1483. URL: http://www.bts.senac.br/index.php/bts;

- 2018 - Emissão de 1 parecer para a revista "Indagatio Didactica", editada pelo Centro de Investigação Didática e Tecnologia na Formação de Formadores (CIDTFF/UA) da Universidade de Aveiro - ISSN 1695-288X. URL: http://indagatio-didactica.web.ua.pt/;

- 2018 - Emissão de 1 parecer para a revista "Amazônida", editada pelo Programa de Pós-graduação em Educação da Universidade Federal do Amazonas - ISSN 2527-014. URL: http://www.periodicos.ufam.edu.br/amazonida;

- 2017 - Emissão de 1 parecer para a revista "Indagatio Didactica", editada pelo CIDTFF/UA - ISSN 1695-288X. URL: http://indagatio-didactica.web.ua.pt/. 
Mediante os objetivos do plano de atividades e das atividades inicialmente delineadas no plano de estágio, foram ministradas duas aulas que tiveram como finalidade dar a conhecer o projeto e seus resultados para além de informar, esclarecer e sensibilizar os estudantes acerca dos riscos e perigos das redes sociais:

- 3 horas de aula no dia 14 de maio do ano letivo de 2017/2018 no $3^{\circ}$ ano da Licenciatura em Educação Básica;

- 3 horas de aula no dia 8 de maio do ano letivo de 2018/2019 no $3^{\circ}$ ano da Licenciatura em Educação Básica.

Um dos objetivos que esteve subjacente ao longo do período de tempo foi a aquisição de novos conhecimentos relativos ao estágio realizado. Nesse sentido, ocorreu a participação em diversos eventos: ticEDUCA 2018; EDULEARN18 Conference; Congresso Internacional de Educação e Tecnologias - CIET : EnPED; II FÓRUM CIDTFF; Congresso E-Tech Portugal' 18; Encontro "Portugal e a Participação Digital de Crianças e Jovens"; I FÓRUM CIDTFF; Research Day 2017; IX Conferência de Tecnologias de Informação e Comunicação na Educação - Challenges' 2017. Também houve participação, no ano de 2018, em cursos de formação: Módulo "How to prepare your manuscript"; Módulo "Systematic reviews 101"; Ação de formação "Seminário Nature Research Editorial Session".

\section{Considerações finais}

O interesse pelo estágio realizado partiu das seguintes questões: Quais os conhecimentos, práticas e perspectivas dos estudantes do ensino superior em relação ao conhecimento dos perigos das redes sociais? Até que ponto os estudantes do ensino superior têm consciência dos riscos e perigos que correm ao disponibilizarem informações pessoais, publicarem fotos, comentários, vídeos e a partilharem publicações nas redes sociais? Como promover a divulgação da temática "Perigos das Redes Sociais" junto aos estudantes do ensino superior?

Assim, as reflexões decorrentes do estágio de pós-doutorado realizado apontam no sentido de que os estudantes são utilizadores das redes sociais, mas não parecem ter a consciência dos riscos, quanto à privacidade e segurança, que correm por causa de suas atitudes, pois utilizar as redes sociais de forma consciente e segura implica compreender os riscos inerentes e adotar algumas atitudes para minimizar esses riscos.

Nesse sentido, considerou-se que a promoção de ações de sensibilização junto aos estudantes possa vir a sanar essa necessidade que se faz urgente em uma sociedade cada vez mais envolvida nos sites de redes sociais. Porém, nesse processo é de extrema importância que as Universidades/Institutos Politécnicos deem retorno às solicitações que os pesquisadores fazem, pois podem impactar uma parte da sua pesquisa, como foi o caso aqui apresentado. 
Há de se ter em consideração que, ao fazer parte de uma rede social, é preciso rever o conceito de privacidade, pois nesse contexto os utilizadores fazem questão de se autopromoverem e com isso colocam em risco tanto a sua privacidade como a sua segurança.

É sempre um desafio sair da sua zona de conforto

O estágio que deu origem a este artigo permitiu responder às questões de pesquisa formuladas e alcançar os objetivos propostos. A esse último nível, contudo, reconhece-se que não foi possível concretizar um dos objetivos iniciais do plano de atividades, que consistia em conseguir promover ações de sensibilização, por meio de palestras, da temática "Perigos das Redes Sociais" junto aos estudantes, palestras essas que seriam proferidas durante os meses de novembro de 2018 a maio de 2019. Objetivo que não foi possível concretizar, em virtude da dificuldade de contato para marcar as palestras com Universidade/Institutos Politécnicos.

Importa referir, também, que o estágio realizado sob a supervisão da professora Doutora TMBC esteve além das expectativas, não só em relação ao seu lado profissional, no que se refere ao trabalho e acompanhamento dispensado ao longo dessa jornada - o que possibilitou acima de tudo uma oportunidade de aprender e dar continuidade ao percurso científico-investigativo - mas principalmente o seu lado humano e sempre acolhedor; o que autoriza afirmar que esses foram um dos grandes benefícios e uma das razões que levaram a cabo esse estágio.

Assim, acredita-se que essa experiência poderá motivar outros pesquisadores, em especial, os brasileiros, a procurarem realizar estágio de pós-doutorado em universidades portuguesas. Porém, é sempre um desafio sair da sua zona de conforto e ir para um outro país, mesmo para quem já está em um nível de investigação avançado, como é o caso dos estágios de pós-doutorado, que são estudos autônomos.

\title{
Nota
}

${ }^{1}$ Mais informações em https://www.hostgator.com.

\section{Referências}

AGENDA Portugal Digital. Portugal: República Portuguesa, [2012]. Disponível em: http://www.portugaldigital.pt/index/. Acesso em: 12 jul. 2019.

\author{
BOTTENTUIT JUNIOR, J. B. Concepção, avaliação e dinamização de um portal \\ educacional de WebQuests em língua portuguesa. 2010. Tese (Doutorado \\ em Educação) - Universidade do Minho, Braga, 2010. Disponível em: http:// \\ repositorium.sdum.uminho.pt/handle/1822/11889. Acesso em: 10 jul. 2019.
}


CARMO, H.; FERREIRA, M. M. Metodologia da investigação: guia para autoaprendizagem. 2. ed. Lisboa: Universidade Aberta, 2008.

COHEN, L.; MANION, L.; MORRISON, K. Research methods in education. 6. ed. London: Routledge, 2007.

HILL, M. M.; HILL, A. Investigação por questionário. Lisboa: Edições Sílabo, 2000.

MACHADO, C.; BETTENCOURT, T. BeSafe: privacidade e segurança nas redes sociais. In: FÓRUM CIDTFF, 1., 2017, Aveiro. Anais... Aveiro: UA Editora, 2017 a.

MACHADO, C.; BETTENCOURT, T. BeSafe: privacy and security in social networks. In: RESEARCH DAY, 2017, Aveiro. Anais... Aveiro: UA Editora, 2017b.

MACHADO, C.; BETTENCOURT, T. Desenho e construção do questionário sobre privacidade e segurança nas redes sociais. In: CONGRESSO INTERNACIONAL TIC E EDUCAÇÃO, 5., 2018; TICEDUCA, 2018, Lisboa. Anais... Lisboa: Universidade de Lisboa, 2018a. Disponível em: https://ead.ulisboa.pt/pluginfile.php/20912/mod_ resource/content/1/atas_ticeduca_2018.pdf. Aesso em: 11 jul. 2019.

MACHADO, C.; BETTENCOURT, T. Evaluating the usability of educational project website: a case study. In: EDULEARN18, 2018, Palma. Conference proceedings. Valencia: IATED Academy, 2018b. p. 9532-9539.

MACHADO, C.; BETTENCOURT, T. O lado negro das redes sociais quais os riscos e como me proteger? IE Comunicaciones: revista iberoamericana de informática educativa, Madrid, n. 28, p. 9-19, jul./dic. 2018c. Disponível em: http://161.67.140.29/iecom/index.php/IECom/article/view/308/302. Acesso em: 11 jul. 2019.

MACHADO, C.; BETTENCOURT, T. Privacy and security in social networks: the virtual is real. In: EDULEARN18, 2018, Palma. Conference proceedings. Valencia: IATED Academy, 2018d. p. 9320-9325.

MACHADO, C.; BETTENCOURT, T. Projeto BeSafe: os estudantes do ensino superior português e a utilização das redes sociais: alguns resultados. In: FÓRUM CIDTFF: CONSTRUINDO UM COMPROMISSO COM A CIÊNCIA ABERTA, 2., 2018, Aveiro. Livro de posters. Aveiro: UA Editora, 2018e.

MACHADO, C.; BETTENCOURT, T. Projeto BeSafe: utilizar as redes sociais com responsabilidade e segurança. In: CONFERÊNCIA INTERNACIONAL DE TIC NA EDUCAÇÃO: CHALLENGES, 10., 2017, Braga. Anais [...] Braga: [s. n.], 2017c. 
MARCONI, M. A.; LAKATOS, E. M. Fundamentos de metodologia científica. 5. ed ed. São Paulo: Atlas, 2003.

PORTUGAL INCoDe.2030: Iniciativa nacional competências digitais e.2030. Lisboa: República Portuguesa, 2017. Disponível em: http://www.incode2030.pt/. Acesso em: 11 jul. 2019.

RUBIN, J.; CHISNELL, D. Handbook of usability testing: how to plan, design, and conduct effective tests. 2nd ed. Indianapolis: Wiley Publishing, 2008.

SILVA, R. C.; FERREIRA, M. D. A.; APOSTOLIDIS, T. Doutorado sanduíche como estratégia de internacionalização do conhecimento da enfermagem. Ciência, Cuidado e Saúde, Maringá, v. 13, n. 4, p. 782-787, 2014.

SILVA, S. R. D. Relato de experiência de pesquisa no exterior e aprimoramento da carreira acadêmica: desafios extramuros. Arquivos em Movimento, Rio de Janeiro, v. 8, n. 1, p. 97-103, 2012. Disponível em: https://revistas.ufrj.br/index.php/am/ article/viewFile/9200/7330. Acesso em: 11 jul. 2019. 